Development of GCRC and CTSA Programs at the University of Kansas Medical Center: A Personal 10-year Perspective

Richard J. Barohn, M.D.

University of Kansas Medical Center, Department of

Neurology, Kansas City, KS

Received Feb. 7, 2020; Accepted for publication Feb. 10, 2020; Published online Feb. 26, 2020

\section{Early Beginnings}

Drs. Thomas DuBose (Chair of Medicine) and Richard Barohn (Chair of Neurology) had arrived to KUMC in 2000 - 2001 from the University of Texas system where General Clinical Research Center's (GCRC) were an important infrastructure component for researchers. Dr. DuBose had called one meeting in 2001 to discuss the possibility of a GCRC at KUMC. Dr. Barohn and others attended but there were no minutes recorded from that meeting. Dr. DuBose left KUMC shortly thereafter (to be Chair of Medicine at Wake Forest Medical Center). After several months Dr. Barohn asked the executive dean, Dr. Barbara Atkinson, if he could restart the initiative and was given permission to form the GCRC planning committee. It should be noted KUMC had a GCRC once before for one funding cycle in the early 1970s. Drs. Jared Grantham and Areyh Hurwitz, who were on the GCRC Planning Committee, were at KUMC during that time.

The Process Begins: Initial Goals. We began the process of initiating a GCRC for The University of Kansas Medical Center (KUMC) campus in 2002. At that time we established four goals:

- Provide clinical investigators from the School of Medicine, School of Nursing and School of Allied Health (as it was then called) with a modern, state of the art facility in which clinical research could be conducted.

- Enhance multidisciplinary research across departments and the three schools.

- Enable and train junior faculty and trainees to become more involved in clinical research.

- Apply for federal funding to support the GCRC.

GCRC Planning Committee. A GCRC planning committee was formed in 2002 and Figure 1 shows the initial members and the commencement of the first official meeting.

This committee met for two years in order to develop the infrastructure needs for the GCRC. Minutes were taken by Dr. Barohn at all committee meetings and prepared by Debbie Jursch, Dr. Barohn's administrative assistant in the Department of Neurology (Appendix A, B, C, D, E, F, G, H, I; available at journals.ku.edu/kjm). As seen in these minutes, Dr. Barohn added a number of additional members quickly, including representation by the Schools of Allied Health (Dr. John Ferraro) and Nursing (Dr. Marge Bott). The committee was active, collegial and lively, but there was some suspicion that we would not be able to pull this off. As we made progress this skepticism disappeared. As I was new to KUMC and had been focused primarily on neurology issues, through this committee I developed close friendships with colleagues across the campus in all these schools including Marge Bott, John Ferraro, Matt Mayo, and Jared Grantham.

\section{KANSAS JOURNAL of MEDICINE}

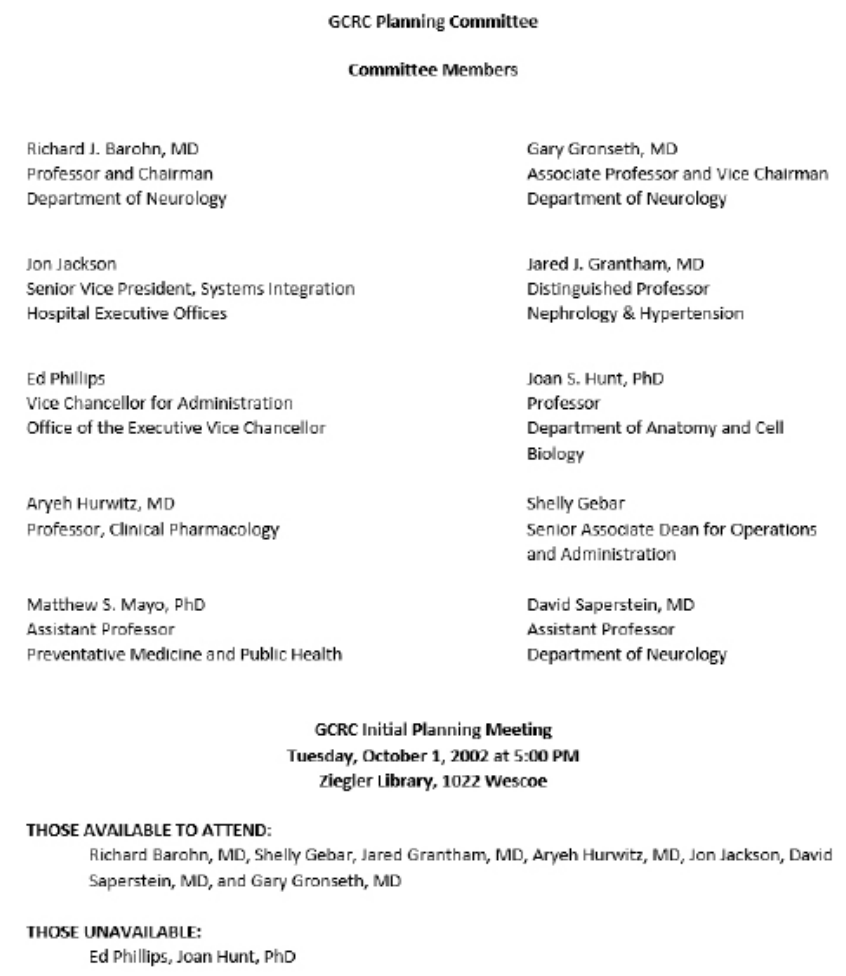

Figure 1. Initial members and commencement of the first GCRC planning committee.

The space in Delp Pavilion was identified (G040 suite of rooms) that had previously been space for the Parkinson's program in the Department of Neurology. The reason the Parkinson's space became available was because the Neurology department had relocated to The Landon Center on Aging. An old driving simulation lab that was no longer used (also in Neurology) in Delp, across the hall from G040, was closed, as was an adjacent ophthalmology office, and these, plus the abandoned radiation therapy space in Delp (G037 suite of rooms), was to become the administrative and nursing offices for GCRC staff. A state-of-the-art metabolic kitchen was installed in one of the G037 rooms through funding by Dr. Joan Hunt, Vice Chancellor of Research. Dr. Deborah Sullivan, Department of Nutrition in the School of Allied Health (as it was then called) directed the metabolic kitchen. There was a lot of discussion on how to organize the clinical GCRC space and we looked at many possible floor plans provided by KUMC architect Steve Smallwood. Originally, the GCRC clinic space had only one bathroom. Dr. Aryeh Hurwitz lobbied the planning committee successfully for two bathrooms, one for the staff and one for patients providing specimen samples and his suggestion was adopted. Many of us remember Dr. Hurwitz request fondly and of course he was correct. Dr. Hurwitz died too young from a cardiac arrest in October 2005 but he did get to see the new GCRC open with two bathrooms. Remodeling began in June 2004 and was completed in October 2004. The GCRC officially opened its doors in January 2005 (Figure 2). At the same time, we disbanded the GCRC planning committee as its function was completed. 
KANSAS JOURNAL of MEDICINE GCRCAND CTSA PROGRAMSAT KUMC continued.
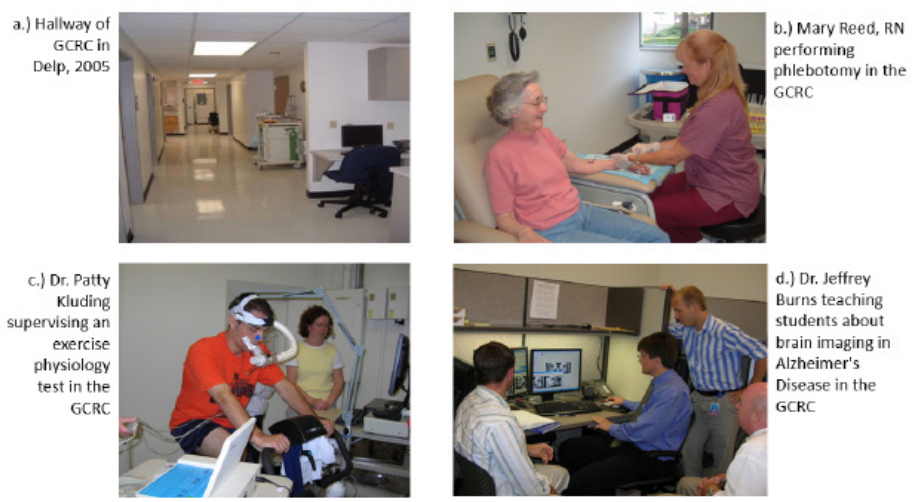

Figure 2. GCRC in 2005.

\section{Foundation of the GCRC Advisory Committee}

Drs. Barbara Atkinson and Richard Barohn announced the formation of the (GCRC Advisory Committee) GAC in the summer of 2004 and notice went out to all clinical investigators on the KU Medical Center campus to indicate that research applications could be submitted in order to use the new GCRC space and resources. Dr. Barohn asked Dr. John Ferraro (Associate Dean of Research, School of Health Professions) to chair the committee of approximately 20 faculty and GCRC staff (the GAC began reviewing protocols monthly in September 2004). The GAC was a group that took their role seriously when they gave feedback to faculty applying to use the GCRC. When Dr. Patricia Kluding (who was an assistant professor in Physical Therapy) applied to use the GCRC she received intense criticism for her proposal. She rose to the occasion and fixed her protocol. We immediately appointed her to be a member of the GAC so she could be part of the process of reviewing future protocols in order to assist those investigators. She has been a key leader in our clinical research infrastructure ever since.

\section{Initial Internal Funding, Staffing and Organization of the GCRC}

Two primary sources provided the initial funding for the KU Medical Center GCRC since its inception. The majority of the funds were supplied through the Executive Vice Chancellor/Vice Chancellor of Research office at KUMC. Dr. Barbara Atkinson was the Executive Vice Chancellor (EVC) in addition to the Executive Dean of the School of Medicine and Dr. Joan Hunt was the VCR. Funds were provided for renovation of space, office supplies and computers, and most significantly nursing, administrative and biostatistical personnel. In addition, the University of Kansas Hospital generously provided all initial equipment and medical supplies in the clinical research areas, including a metabolic cart, electrocardiogram, freezers, and centrifuges. All of this financial support was provided in anticipation of an NIH grant submission. Mr. Jon Jackson, one of the KU Hospital vice presidents, was the primary champion to develop GCRC. In addition, some funds were obtained from the Kansas City Area Life Sciences Institute that was used to hire research nurses. Dr. Barohn received a planning grant from the Research Institute to prepare the GCRC application. Dr. Barohn invited Judy Otey, RN, from the GCRC at the University of Texas Southwestern in Dallas to be the Chief Nurse of the GCRC. Dr. Barohn had worked in the GCRC at UTSW and he was introduced to Ms. Otey as a potential candidate to be the nurse and GCRC leader in Kansas. He and Ms. Otey hired Suzie Schmidt to be the administrative director, Nicole Ladisech to be the administrative assistant and Mary Reed, RN, to be a clinical research nurse (Figure 3 ).

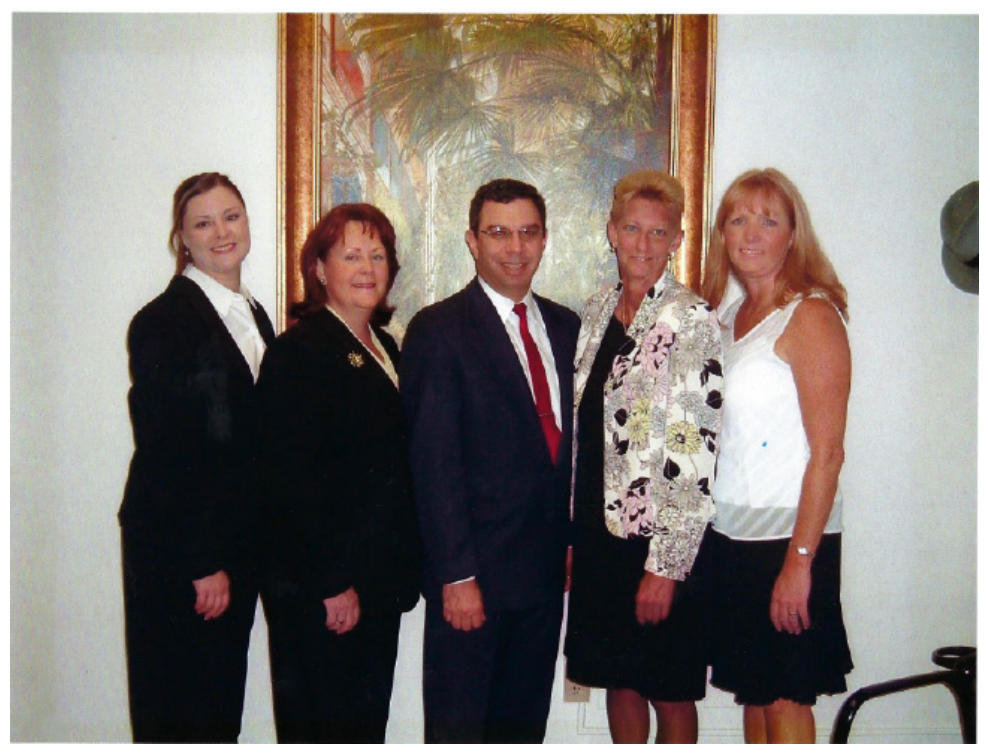

Figure 3. Initial GCRC leadership and staff (January 2005 Grand Opening). Left to right: Nicole Ladisech, Suzie Schmidt, Richard J. Barohn, Judy Otey, Mary Reed.

Shortly after construction in the initial Delp GCRC space began, KU Hospital announced they would be closing the old mechanics machine shop (located in Delp in the rear of the old radiation therapy room, Delp G036). Dr. Barohn obtained this space from KU Hospital, and funds for remodeling, so that it would become the initial exercise physiology laboratory in the GCRC. The exercise physiology space was large and well equipped and used by all three schools. It was a major factor in recruiting Dr. Jeffrey Burns to the Department of Neurology to begin the Alzheimer's Disease program which was to have an exercise and metabolic focus. The initial organization of the GCRC is displayed in Figure 4. Dr. Barohn has recorded parts of the development of the GCRC KU study at the Merrill Retreat sponsored by KU-Lawrence in $2016 .{ }^{1}$

\section{GCRC NIH Grant}

Simultaneous with the development of a functioning GCRC, a grant application was prepared. We notified the NIH/NCRR of the development of our GCRC at KU Medical Center and they had scheduled us to submit our proposal in 2006. The KU Medical Center GCRC NIH grant application was submitted on June 1, 2006 and was funded in the spring of 2007 for three years at approximately $\$ 3$ million dollars/year. It was the last new GCRC application funded by the NIH. The NIH officials informed Dr. Barohn that the Clinical and Translational Science Award (CTSA) was being initiated, and that this would replace the GCRC program. They advised Dr. Barohn to submit the GCRC application, but said "if funded it would only be for three years and after that time KUMC would have to obtain a CTSA grant.” They also told Dr. Barohn that there would be an opportunity to apply for a CTSA planning grant. 


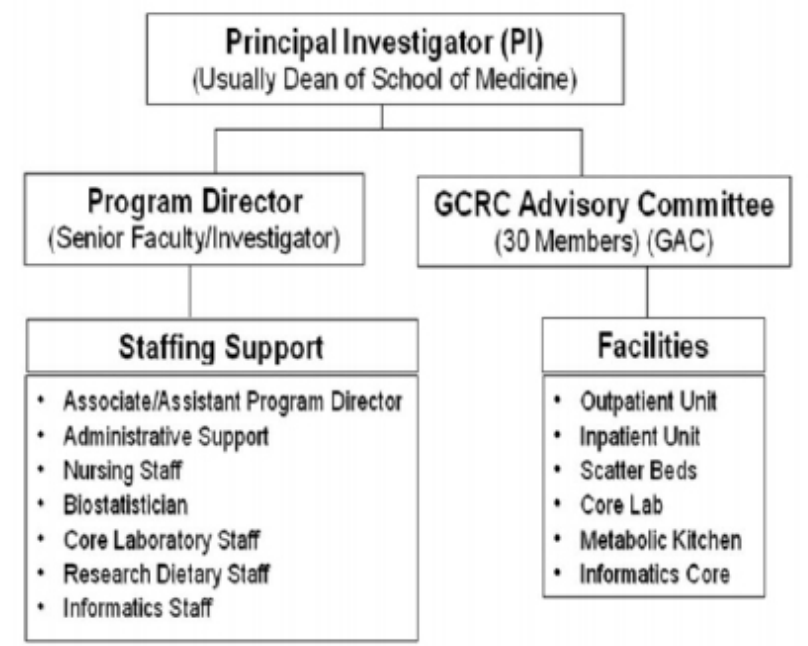

Figure 4. Initial organization of the GCRC.

\section{Announcement of the Clinical and Translational Science Award Program}

In September 2005, the NIH released an RFA announcement for institutional Clinical and Translational Science Awards (CTSA). The stated purposed for the CTSA project was to forge a transformative and integrative academic home for clinical and translational science. Dr. Zerhouni, the NIH Director, stipulated that these new homes in academic health centers would be a center, department, or institute. These clinical research units were to encompass all components of clinical research, including education, career development, and regulatory components for clinical research infrastructure. ${ }^{2}$ These new clinical research units were to promote multi-disciplinary research teams, create an incubator for innovative research tools, and catalyze the application of new knowledge to clinical practice. These clinical research units were to also provide degree-granting capabilities in clinical research that will lead a trainee to either a masters or a doctorate degree.

The clinical research infrastructure provided by GCRCs were to be incorporated into the larger CTSA awards. By doing so, this would give academic health centers greater flexibility in modeling clinical research infrastructure space for the future. In this new model, there were potentially fewer restrictions on collaborations with industry in developing clinical research programs at academic health centers. There was no restriction on number of industry sponsored studies or in the amount of funds that a clinical research center can receive from industry. Under GCRC rules this was not the case.

\section{Planning Process for the CTSA at KUMC and the Kansas City Region}

Shortly after the RFA for the new CTSA awards, a planning process was initiated at KU Medical Center to develop our university's response to this new program. ${ }^{3}$ The various planning committees and subcommittees were established in October 2005 (Figure 5) and began meeting regularly.
KANSAS JOURNAL of MEDICINE GCRCAND CTSA PROGRAMS AT KUMC continued.

\begin{tabular}{|c|c|c|}
\hline CTSA COMMITIEE & CHAIR(S) & PURPOSE \\
\hline Flanning Steering Comrritles & $\begin{array}{l}\text { Barbara Askinson, MD } \\
\text { Richard Barohn, MD }\end{array}$ & $\begin{array}{l}\text { Direct and oversee entre planning } \\
\text { process }\end{array}$ \\
\hline Govemance Planning Sub-Commitlee & $\begin{array}{l}\text { Fichard Barohn, MD } \\
\text { Barthard Assinson, MD } \\
\end{array}$ & $\begin{array}{l}\text { Develop and propose overall } \\
\text { governance and structure of HICR }\end{array}$ \\
\hline Grant Wning Planning Sub-Committee & $\begin{array}{l}\text { Rachard Baronn. MD } \\
\text { Lauren Aaronson, PhD, RN }\end{array}$ & Wrte the full NIH CTSA apolication \\
\hline Education Planning & Ed Ellerbeck, MD, MPH & $\begin{array}{l}\text { Dowolop K-12 and T-32 training } \\
\text { programs for the ful CTSA application; } \\
\text { propose mechanisms to coordinate and } \\
\text { incorporate existing traning programs } \\
\text { (e. . K30, Other T328) }\end{array}$ \\
\hline Clinical Research Resources Planning & Richard Barohn, MD & 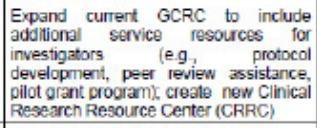 \\
\hline Clinical Pilots Planning Sub-Cormittee & $\begin{array}{l}\text { John Ferraro, PhD } \\
\text { Ted Knous, PhD }\end{array}$ & $\begin{array}{l}\text { Create policies \& procedures for support } \\
\text { of cinical \& pllot sudies in pronty areas } \\
\text { within the CRRC }\end{array}$ \\
\hline Biostatistics \& Informatics Planning & Matt Mayo, PnD & $\begin{array}{l}\text { Desicn expanded infrastructure and } \\
\text { procedures tor biostatistician and } \\
\text { informatics support }\end{array}$ \\
\hline Regulatory Planring & $\begin{array}{l}\text { Jim Voogt, Pho } \\
\text { John Finley, JD }\end{array}$ & $\begin{array}{l}\text { Develos mecharisms to support } \\
\text { investigators with to reguatory } \\
\text { requirernents }\end{array}$ \\
\hline $\begin{array}{l}\text { Novel Methods \& Translational } \\
\text { Technologies Planning }\end{array}$ & $\begin{array}{l}\text { Curt Hagedom, MD } \\
\text { Paul Terranova, PhD }\end{array}$ & $\begin{array}{l}\text { Cocrdinate use of technologies } \\
\text { applicable to clinical research and } \\
\text { propose new methodologies }\end{array}$ \\
\hline Heath Dispanties Research Planning & $\begin{array}{l}\text { Patricia Thomas, MD } \\
\text { Kitry Randolph, FhD }\end{array}$ & $\begin{array}{l}\text { Design Health Disparites Research } \\
\text { Center with resources and services to } \\
\text { integrate dspanties issues in all cinical } \\
\text { research }\end{array}$ \\
\hline Community \& Participant Planning & $\begin{array}{l}\text { Joshtua Freemlan, MD } \\
\text { Lauren Aaronson, PhD, RN }\end{array}$ & $\begin{array}{l}\text { Create poicies and procedures for } \\
\text { provider and study participant } \\
\text { involvement in the HICR and } \\
\text { mechanisms for regular communication }\end{array}$ \\
\hline Regional Academic Institution Planning & Jim Voogt, Pno & $\begin{array}{l}\text { Develop formal partnership agreements } \\
\text { with current partners and explore } \\
\text { inclusion of other instiutions from the KC } \\
\text { area }\end{array}$ \\
\hline Private Sector Commercialization Plarning & $\begin{array}{r}\text { Scott Weir, PhD } \\
59\end{array}$ & $\begin{array}{l}\begin{array}{l}\text { Identify opportunities for clinical \& } \\
\text { transtastonal research with private } \\
\text { industry }\end{array} \\
\end{array}$ \\
\hline
\end{tabular}

Figure 5. CTSA planning committees and sub-committees.

The timeline was that applications had to be submitted to the NIH by March 27, 2006. At that time, the NIH was accepting two types of applications. The first was a planning grant for $\$ 150,000$ that would allow academic health centers time and some resources to further develop a global CTSA application. The second type of grant was a full CTSA application that could be as large as $\$ 6$ million dollars per year if pediatric clinical research was involved; up to $\$ 4$ million dollars without clinical pediatric research. In addition to the \$6 million dollar per year CTSA award, all existing K30, T32, and GCRC grants were to be rolled in the CTSA application. By doing so, a full CTSA application would become one of the largest institutional research grants that an academic health center could receive. The stated goal of the NIH was to fund 60 small CTSA planning grants and five to seven full CTSA grants in the first round of applications. Their ultimate goal was to fund 60 full CTSA awards throughout the United States by 2012.

As our planning committees met, we recognized there would be a number of weaknesses and strengths for KU Medical Center CTSA application. The weaknesses included:

- No current GCRC NIH funding

- No clinical T32 training grants

- Relatively small number of clinical mentors and mentors with current clinical Rl grants 
KANSAS JOURNAL of MEDICINE GCRCAND CTSA PROGRAMS AT KUMC

continued.

The strength of KU Medical Center CTSA application included:

- The existing NIH funded K30 program and the Masters of Science and Clinical Research Program

- The current existing GCRC infrastructure (before it was funded)

- The Research Institute at KU Medical Center

- The multidisciplinary and collaborative research efforts between the School of Medicine, School of Nursing and School of Allied Health (which became the School of Health Professions)

- A strong bioinformatics center

- Strong ties with programs at the University of Kansas-Lawrence Campus, particularly drug development and the Lifespan Institute

- Potential strong ties with partners in the community, other regional academic centers and in private industry

As a result of the CTSA planning process, it was decided to submit a CTSA planning grant before the March 2006 deadline.

Lauren Aaronson, Ph.D., RN, came to KUMC School of Nursing in 1989 as the Associate Dean for Research. In 2004 she went to the NIH in Bethesda as a senior advisor to the director of the National Institute of Nursing Research (NINR) as part of an interagency personal agreement between NIH and KUMC to join the new Roadmap for Research Initiative. One of her duties was to help craft components of the emerging CTSA plan and research announcement. Drs. Barohn and Burns attended the NIH event to announce the CTSA program in the Fall of 2005 and they met Dr. Aaronson. Dr. Aaronson's time at the NIH ended in December 2005 and she returned to KUMC. She immediately joined Dr. Barohn to begin the CTSA Planning Grant application. Dr. Barohn took the lead in preparing the GCRC grant and Dr. Aaronson took the lead in preparing the CTSA Planning Grant, but they worked on each application intensely. Both were submitted within four months of each other. They remained research grant 'partners' for the next 10 years, when Dr. Aaronson retired.

\section{Concept of a Heartland Institute for Clinical Research}

Our CTSA planning grant application outlined the concept of a new Heartland Institute for Clinical Research (HICR) as a new integrated home for clinical and translational research, both at KU Medical Center and in the region. We anticipated that the HICR would consist of many centers, and each center would have a number of cores or programs (Figures 6 and 7). ${ }^{3}$

The education center would house the existing Masters of Clinical Research and K30 programs and new additional K12 and T32 career development awards that can provide significant salary support and thus release time so that young investigators can pursue training in clinical research. The education center also encompassed developmental programs, including a recently initiated Introduction to Clinical Research course that was launched in the fall of 2006 semester, as well as a proposed Research Coordinator Training Program that was under development.

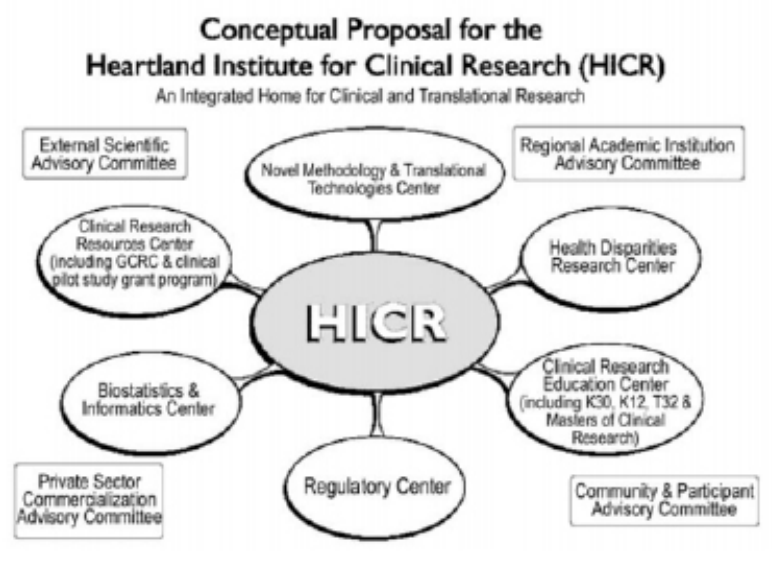

Figure 6. Early conception of HICR, 2006.

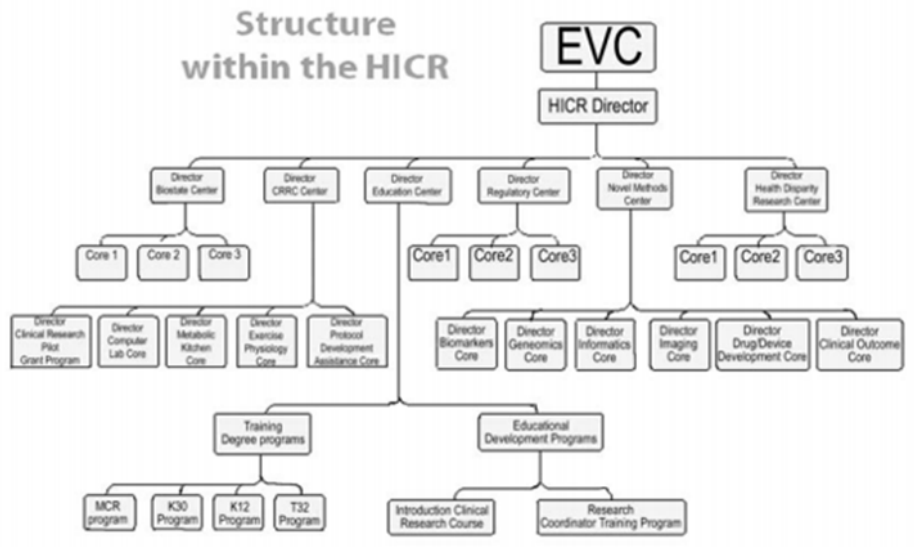

Figure 7. Early structure of HICR, 2006.

The current GCRC would be incorporated into a new Clinical Research Resource Center (CRRC). The CRRC would also include a Clinical Research Pilot Grant Program where a junior investigator can apply for up to $\$ 25,000$ seed funds for a new clinical research project. The CRRC would also contain a new protocol development/ assistance core to aid a new investigator in preparing a grant submission. Within the Novel Methodology and Translational Technologies Center, core technologies to facilitate translational research would be housed. An investigator would be able to apply to the Novel Methodology and Translational Technologies Center for access to these individual cores for their research protocols. For example, if a pilot project required brain imaging at the Hoglund Brain Imaging Center, the investigator would apply to the Novel Methodology and Translational Technologies Center for funding and intellectual support. In addition, we planned to establish four important committees that would bring in partners from the external scientific community, the regional academic centers, the private sector, and lay community organizations and institutions.

Plans to Create a Regional Translational Clinical Research Center

In the early CTSA planning stages in 2006, Dr. Barohn and KUMC leadership believed that including other partners in the program would raise the level of research in the Kansas City region. As Dr. Barohn was a graduate of the UMKC School of Medicine, this seemed natural and he still had ties to UMKC, Truman Medical Center, Children's Mercy Hospital and St. Luke's Medical Center. He asked for meetings with various leaders of these institutions to explain the new CTSA program and how obtaining a CTSA award could benefit researchers at all of these institutions. 
Initially in these meetings, there was no immediate buy-in to the plan. Over a series of meetings, the cross-town hesitancy to collaborate softened and by the time the CTSA planning grant was submitted the concept of a regional enterprise was a component of the future HICR (Figure 8).

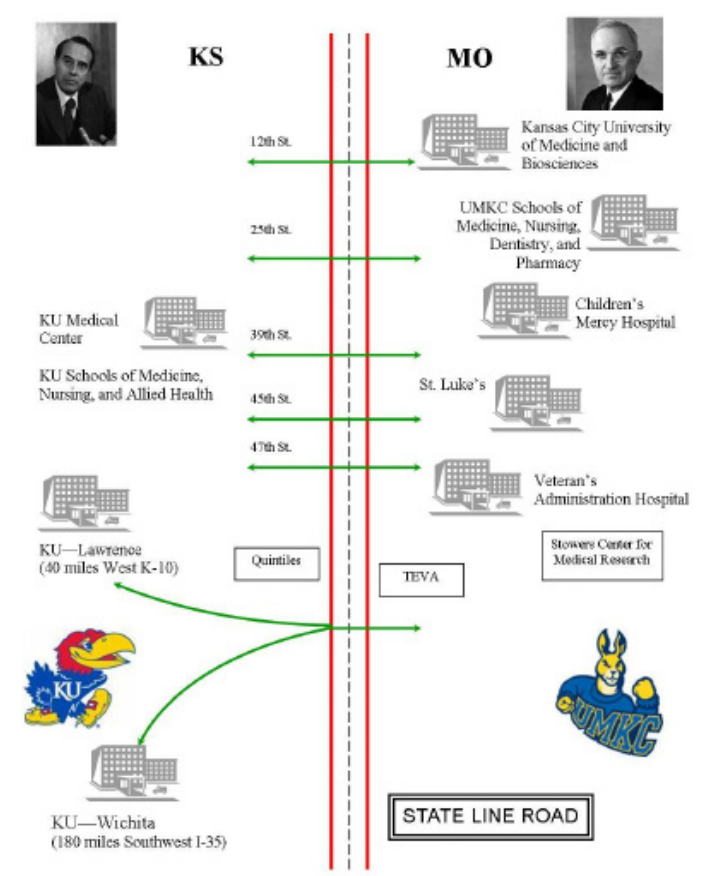

Figure 8. Regional partnership plan for HICR, 2006.

After the planning grant was submitted in March 2006, Dr. Barohn continued to have meetings with leaders in Missouri, to determine who could be included from these institutions in the Fall CTSA submission. Dr. Barohn found welcome partners in the School of Medicine, including Dr. Gary Salzman who was a classmate of Dr. Barohn's. He also met frequently with leaders of Children's Mercy Hospital research unit, one of which was Dr. Ralph Kauffman. Steve Leeder, Pharm.D., Ph.D., at CMH also became involved. Dr. Barohn was introduced to Dr. John Spertus at St. Luke's who ultimately would become a leader in the CTSA program.

The Kansas City VA Medical Center was initially included as a partner as well. And of course, all KU Faculty on the Lawrence campus and in the Wichita School of Medicine were all partners. The concept was that if an institution was a partner in the HICR, then all the faculty of that institution would have access to the components of the institute.

The name of the institute was ultimately changed to the HICTRHeartland Institute for Clinical Translational Research. Views were split on how favorable or unfavorable the acronym HICTR was perceived. Dr. Atkinson often expressed her unfavorable view. But the acronym HICR was used for the CTSA planning grant submission in 2006, and HICTR for the full grant submission.

Both the GCRC and CTSA planning grants were funded in 2007. The planning grant was small, providing $\$ 150,000$ direct funds for one year compared to GCRC grant ( $\$ 3$ million dollars/year for 3 years.)

For 12 months the HICTR grant writing team prepared the large paper application that was submitted in 2008. The Office of Grants and Research in the SON and Dr. Marge Bott (Associate Dean for
KANSAS JOURNAL of MEDICINE GCRC AND CTSA PROGRAMS AT KUMC continued.

Research, SON) and her staff played a critical role in the grant preparation and assembly, along with the GCRC staff. Dr. Atkinson had announced the official launch of the HICTR several months before the grant submission, with Drs. Barohn and Atkinson as director and co-director, respectively. An event was held at Union Station to celebrate the launch of the HICTR and was well attended by leaders from all partner institutions.

We received our score in February 2009. It was not good - 311. In fact, it was a terrible score. I recall Dr. Aaronson calling me with the score when I was away in Dallas and she said "Rick, are you sitting down? If not, you need to." But we believed we could fix the critiques. In the Fall of 2009, we resubmitted. In February 2010, we got our score, which was much better, but still not fundable - 31. The NIH had moved to a two-digit grading system and a perfect score was 10. In the critiques it was clear a major problem was our informatics program. We assembled an External Advisory Board led by Dr. Claire Pomeroy (Dean of the School of Medicine, University of California, Davis) and other leaders from institutions with CTSA grants. They gave us a clear idea of how we could improve the application. We began a search for an informatics leader. We recruited Dr. Russ Waitman to fill this role. Dr. Waitman arrived in 2010 and rewrote the informatics section as he simultaneously set up a system to extract medical data from the Epic electronic medical record for research using the I2b2 software and a new program code he and his team wrote. He called the program HERON. HERON quickly became a highly useful research tool for faculty.

The CTSA application was submitted for a third time by Drs. Barohn and Aaronson and their team in the fall of 2010. In February 2011, we received our score while Drs. Barohn and Aaronson were in Dr. Atkinson's EVC office. At the beginning of their meeting, no score had been posted. Forty-five minutes later Dr. Atkinson checked again. The score was 14. The three professors yelled "Fourteen!" and as I recall there was a three-person hug and some jumping up and down.

Two other major changes occurred in our CTSA program. In addition to hiring external consultants, we had internal brainstorming sessions to see if there was a better name than HICTR for our program. C.J. Janovy, our director of communications at the time, came up with the name Frontiers. It seemed perfect and although I hated to give up HICTR, I was clearly in the minority and since then we are Frontiers. Both regional and nationally, we are Frontiers. We made this name change after we were funded in 2011.

The other major change was the Johnson County Education Research Triangle (JCERT) initiative and the move to Fairway. Dr. Atkinson and her leadership team, with the help of local community leaders, accomplished the amazing fete of getting a sales tax for research passed by the voters of Johnson County in November 2008, in the middle of a severe recession. This sales tax provided funds in perpetuity for KUMC research at two office buildings (purchased by the Hall Foundation and donated to KUMC) in what is now our 
KANSAS JOURNAL of MEDICINE GCRC AND CTSA PROGRAMSAT KUMC

continued.

Fairway campus. The tax also provides funds for the KU Edwards Campus and to the K-State Olathe campus. The KUMC Fairway funds paid for renovations of the buildings and on-going maintenance and operations. A major focus of the Fairway campus was to create a phase 1 trial unit for the cancer institute on the second floor. We moved the GCRC to the third floor and called it the Clinical Translational Science Unit (CTSU). This is what we called the unit when we submitted the CTSA grant in 2010 and we moved into the new unit just before the grant submission. The new CTSU was a major expansion. We now had 23 research rooms to see research participants, and a large infusion suite with eight bays, a large exercise lab, a large metabolic kitchen, and three extended stay rooms with beds for patients who needed extended stays for $\mathrm{PK} / \mathrm{PD}$ studies. In this new expanded CTSU, Dr. Jeffrey Burns became the director in 2011. Dr. Burns was recruited to KUMC because we were opening a GCRC in 2006 and we built an exercise unit in large part for his research needs as noted above. Therefore, this was another example of a junior faculty member using the GCRC who eventually moved into a leadership role in Frontiers.

In July 2011, Frontiers was funded at $\$ 4$ million dollars a year for five years. In the fall of 2010 Drs. Russ Swerdlow and Jeffrey Burns were funded for an NIH Alzheimer's Disease Center. Also, in 2011 Dr. Roy Jenson and his team were funded for a NIH Cancer Center. All three centers were funded within 12 months. The year 1905 has been referred to as Einstein's “Annus mirabilis” because he had four groundbreaking papers published that year and he went from obscurity to worldwide recognition. ${ }^{4}$ While probably not as scientifically and culturally significant as Einstein's 1905 breakthroughs, the 12 months in 2010 and 2011 was KUMCs "annus mirabilis" and pulled KUMC research from obscurity to national relevance.

\section{FUNDING SUPPORT}

This work was supported by a CTSA grant from NCATS awarded to the University of Kansas for Frontiers: University of Kansas Clinical and Translational Science Institute (\#ULlTR002366). The contents are solely the responsibility of the author and do not necessarily represent the official views of the NIH or NCATS.

\section{REFERENCES}

1. Barohn RJ. Clinical research resources at the University of Kansas Medical Center: General Clinical Research Centers (GCRC) and Clinical Translation Science Awards (CTSA). Merrill Advanced Studies Center, Report 2006; 110:51-60.

2. Zerhouni EA. Translational and clinical science - time for a new vision. $\mathrm{N}$ EnglJ Med 2005; 353(15):1621-1623. PMID: 16221788.

3. Barohn RJ, Aaronson LS. The General Clinical Research Center (GCRC) and The Heartland Institute for Clinical and Translational Research (HICTR) at the University of Kansas Medical Center (KUMC). Merrill Series on The Research Mission of Public Universities 2007; 111:32-43.

4. Gribbin M, Gribbin J. Annus Mirabilis: 1905, Albert Einstein, and the Theory of Relativity. New York, NY: The Penguin Group, 2005.

Keywords: GCRC, CTSA, Frontiers

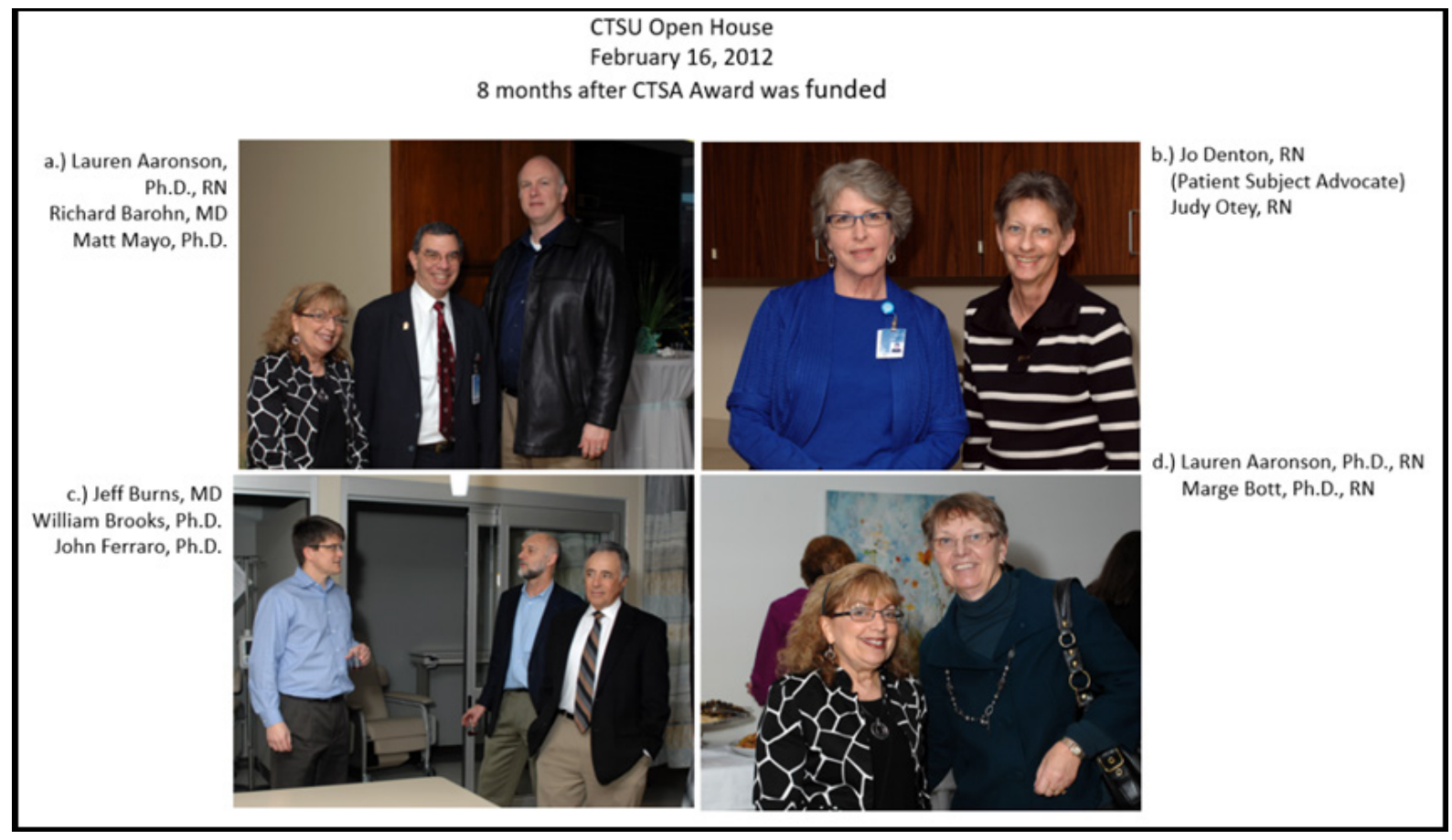

